This item was submitted to Loughborough's Research Repository by the author.

Items in Figshare are protected by copyright, with all rights reserved, unless otherwise indicated.

\title{
Managing reuse in manufacturing system modelling and design: a value net approach
}

PLEASE CITE THE PUBLISHED VERSION

http://dx.doi.org/10.1080/09511920310001607122

PUBLISHER

(c) Taylor \& Francis

VERSION

AM (Accepted Manuscript)

LICENCE

CC BY-NC-ND 4.0

\section{REPOSITORY RECORD}

Dani, Shilpa S., and Jennifer A. Harding. 2019. "Managing Reuse in Manufacturing System Modelling and Design: A Value Net Approach". figshare. https://hdl.handle.net/2134/9801. 
This item was submitted to Loughborough's Institutional Repository (https://dspace.lboro.ac.uk/) by the author and is made available under the following Creative Commons Licence conditions.

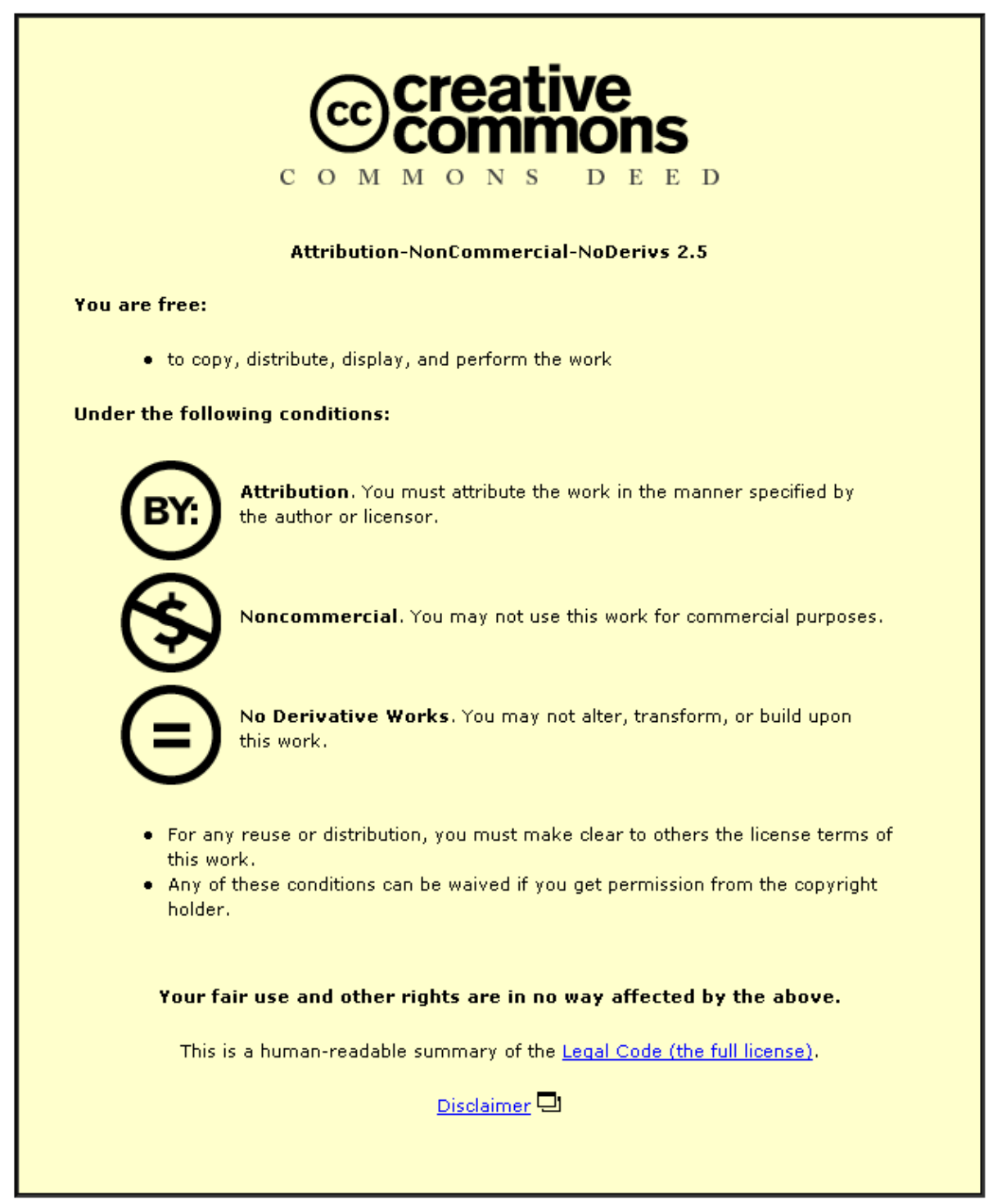

For the full text of this licence, please go to: http://creativecommons.org/licenses/by-nc-nd/2.5/ 
Revised Version

Page 1 of 21

\title{
Managing reuse in Manufacturing System modelling and design: a value net approach
}

\author{
Shilpa. S. Dani \\ Wolfson School of Mechanical and Manufacturing Engineering, \\ Loughborough University, Loughborough, Leicestershire, LE11 3TU, UK. \\ e-mail:S.Dani3@lboro.ac.uk \\ Jenny A. Harding \\ Wolfson School of Mechanical and Manufacturing Engineering, \\ Loughborough University, Loughborough, Leicestershire, LE11 3TU,UK. \\ e-mail:J.A.Harding@lboro.ac.uk
}

\begin{abstract}
In the past, reuse programs have assumed that technical solutions would overcome barriers to effective reuse. However, recent retrospectives of reuse programs show that organizational factors can greatly affect the implementation of a reuse program. Reuse is often approached as an independent collection of tools and techniques, and the technical and non-technical aspects are commonly examined separately. This research proposes that all the factors affecting reuse are interdependent and therefore should be studied simultaneously. It is therefore very important that all elements and relationships are identified and documented in a structured, clear manner. The concept of value nets, based on game theory has been identified as a means of capturing the different factors involved in the reuse driven software process. The value net is a useful model for viewing multiple interactions from various perspectives. The value net of the reuse driven software development process is a map of the various factors and players identified in the reuse process, and the interactions occurring between the players. Hence the reuse value net helps in identifying the important factors that can provide the points of leverage to make the reuse process more efficient.
\end{abstract}

\section{Introduction}

Manufacturing system design or redesign generally includes some elements of modelling and simulation, so that the current system and processes can be better understood, and the changes, or new system and processes, can be evaluated before expensive modifications are implemented (Harding \& Popplewell, 1998) (Harding et al, 1999). Building models of all types is an expensive process as it takes considerable time and effort to fully analyse and understand the systems and processes, that form an essential part of the operation of an enterprise, but this knowledge must be gained before appropriate enterprise or simulation models may be built. Models must also be appropriate to meet the objectives of the project and tasks that they have been built to support. It can therefore be difficult to reuse existing models for other projects, particularly if different personnel are working on the projects. Unfortunately, a large (and expensive) amount of time is generally needed to re-examine all the possible existing models, and modify them as required, hence models are often used for a project and then rejected (and wasted) as new models are built for the next project. This is a waste of information and resources, as some elements of the existing models may well be appropriate for future use. When changes 
must be made within the manufacturing system, the application of an existing design or parts of an existing successful design may help to reduce the resources needed for original design and analysis. It will also help to avoid the error and uncertainty that accompany all human activities and design or development in particular. It also helps maximise the familiarity of production staff with the selected design and helps clients to maintain consistent ways of using and maintaining the result (Busby, 1999).

The research reported in this paper examines ways of reusing existing information, models and software in manufacturing system design. As this is a fairly new area of research, the longer established area of software reuse was initially studied to identify similarities and lessons, which may benefit the current work. Software reuse - broadly defined as the use of engineering knowledge or artefacts from existing systems to build new ones - is a technology for improving software quality and productivity (Frakes \& Isoda, 1994). Software Reuse is the process of creating software systems from predefined software components (McClure, C., 1997). Reuse is not a new strategy, reusing an existing design in a new application is an obvious way of reducing effort and risk - not just in the design activity itself, but also in downstream functions. The potential of reuse has been identified by many researchers and research groups with differing motivations (Sivaloganathan \& Shahin, 1999). In the past, the different factors involved in a reuse process have been identified and studied separately by different research groups. However, the identification of the factors is not sufficient in itself to arrive at a decision about the requirements of an efficient reuse process. All the factors involved in the reuse process play different roles in the reuse process. The authors believe that all the reuse factors are interdependent and hence should be studied simultaneously to achieve an efficient reuse process. Study of the interdependencies between the factors provides knowledge of how a particular factor is affecting the reuse process. To achieve this, the factors have to be depicted in a fashion, which makes it easier to analyse the reuse process. In this research the concept of a value net has been identified as a means of studying the reuse factors. The value net of the reuse driven manufacturing system software development process is a map of the various factors and players identified in the reuse process, and the interactions occurring between the players.

Many companies are not achieving their full potential for reuse, some have had disappointing results from their reuse efforts, but many others are still avoiding reuse altogether. However, the problem is not the lack of technologies to support reuse. The problem arises when organizations approach reuse as an independent collection of tools and techniques, or when an organization focuses purely on the technical issues of reuse without adequately addressing the non-technical issues (Rine \& Nada, 2000). Too often in the past, organizations have treated reuse solely as a technical problem and neglected the welter of other critical factors. Recent retrospectives of reuse programs show that organizational factors can greatly affect the implementation of a reuse program. More recently, many of these issues have been discussed in the literature and at several workshops and conferences. The role of each factor in the reuse process needs to be studied in parallel with the relationship between these factors. This paper presents a novel approach of using Value Nets in order to design an efficient software reuse process. 


\section{The Value Net}

An enterprise generates wealth by operating a business, which produces products or services for a market ( $\mathrm{Yu}$ et al, 2000). In today's business context the imperatives of cost efficiency and customer responsiveness have driven firms to aggressively pursue two common business strategies - globalisation (i.e. the worldwide distribution of production and associated facilities) and time-based competition. Both these strategies have dramatically transformed the way in which business activities are organized and carried out. Globalisation is motivated by pressures like cost-effectiveness, access to new markets and economies of scale (Bhatnagar \& Viswanathan, 2000). It has led to the emergence of borderless organizations with globally distributed suppliers, production and related facilities. Enterprises are under continuous competitive pressure in the market place. However, all businesses cannot be considered to be competitors, there are businesses that complement too. There are also products or services, which provide complementary rather than competing products and services. The Complementors are those who cooperate to capture market share (Nalebuff, Brandenburger, 1996). There are four entities affecting a business that should be considered when developing a business strategy i.e., the suppliers, customers, competitors and the complementors. Nalebuff and Brandenburger introduced a schematic map of a business called 'The Value Net'. The concept of a value net is based on Game Theory, where business is considered as a game. The Value Net is a map of the game of business. The Value Net describes all the players and analyses the elements of competition and co-operation between them. In other words, the value net locates all the various players relative to one another and identifies the interdependencies between them. The research reported here applies the concept of the value net to the reuse process.

In its simplest state, a value net can be visually represented by a diamond, with a company in the centre. The value net can be graphically portrayed as the interactions between four players, i.e. customers, suppliers, competitors and complementors and the company. In the Value Net, along the vertical dimension are the company's customers and suppliers. Resources such as raw materials and labour flow from the suppliers to the company, and products and services flow from the company to its customers. Along the horizontal dimension of the Value Net are the company's competitors and complementors. Complementors are third parties who can lend added value to a firm by supplementing its products and services. For example, a computer manufacturer views a software company as a complementor, because customers place greater value on a computer with an operating system installed than on either the computer or the software alone. The Value Net is a high level view of the key relationships that drive any company's ability to succeed sustainably (Rabbino). Fig. 1 shows a schematic map of the whole game or The Value Net, as presented by Nalebuff and Brandenburger, (1996).

\section{[insert figure 1 about here]}

\section{Applying value net theory to the reuse driven software process}

The value net above is initially drawn from the company's point of view. But the concept extends beyond this single viewpoint, as there are customers' customers, suppliers' suppliers, and so on. The value net can either be extended to represent 
these extended values or separate value nets can be drawn for suppliers, customers, etc. In the context of the present research different reuse factors must be grouped because of their important interdependencies. We therefore now examine the roles of the players, customers, suppliers, complementors and competitors in forming a reuse value net.

\subsection{The suppliers and customers}

In the Value Net suppliers and the customers appear on the vertical dimension, as the customers play symmetric roles with the suppliers. They are equal partners in creating value. Experts and Designers fulfil these roles in the Reuse Value Net. Reuse is about the production and consumption of reuse (Fafchamps, 1994). A producer is a creator of reusable work products, and the consumer is someone who uses them to create other software (Lim, 1994). In the Reuse Value Net, system experts are the 'suppliers' who 'supply' or provide their expert knowledge for reuse. Management also plays a role as a supplier as it provides the funding, resources and additional support environments that are required to enable the reuse process. Designers have 2 roles, both as a 'supplier' and as a 'customer'. The designers may design a component which is subsequently available for reuse. Therefore, in this context, a designer is an expert, who uses his skills to produce a reusable product (hence designers are suppliers). A designer may also reuse a component designed by another designer or take advantage of expert knowledge on reuse (hence designers are also customers). The Organisation is a customer as it wishes to gain the financial and operational benefits that can result from efficient reuse.

The value net shown in figure 2 summarises this range of customers and suppliers.

[Insert figure 2 about here]

\subsection{The competitors and complementors}

On the horizontal dimension of the value net, there is another symmetry, i.e. the competitors and the complementors. A competitor provides the competition to a product and to meet and overcome this competition the quality of the product must be constantly improved (Nalebuff, Brandenburger, 1996). The traditional design methods, which do not promote reuse, are the competitors to the reuse-driven process. One of the reasons for the designers using design processes, which do not involve reuse, is the Not-Invented-Here (NIH) Syndrome (Ambler, 1998). The designers prefer the traditional design methods, which do not promote reuse, and hence are the competitors to the reuse-driven process. Hence, NIH competes against reuse. On the other hand, the members of the organization will be better motivated to practice reuse when there are reuse libraries/catalogues where they can easily find the reusable components. Hence the reuse libraries are the complementors in the Reuse Value Net. However, it is not sufficient to have something to reuse, since designers will not reuse existing components if they feel it is quicker or easier to "design from scratch", than to determine whether an existing component is appropriate for their application. The reuse libraries should therefore be complemented by the knowledge of how to reuse the available components, and by techniques to simplify the reuse of these components. 
Revised Version

Page 5 of 21

$25 / 4 / 03$

[Insert figure 3 about here]

\subsection{The Reuse Value Net}

The previous discussions and figures show that the factors affecting reuse can be mapped using a Reuse Value Net that is based on the concept of a value net as described in section 2. The completed Value Net for Reuse-Driven Software Process can be drawn as shown in fig 4 .

[Insert figure 4 about here]

The Reuse Value Net in figure 4 shows that experts, designers and management are the suppliers of knowledge and funding to the reuse process. Similarly, the designers and organization are the customers as the designers are reusing the expert knowledge and the organization is getting benefit from savings that are made as a result of the reuse process. The competitors to the reuse process are alternative design methods, such as design from scratch, and preconceptions or existing prejudices of personnel involved in the process, such as NIH syndrome as this thinking restricts the designer, preventing him from taking advantage of reusable elements. Finally, the reuse library, knowledge bases, and various reuse tools and techniques are complementors as the reuse library provides the reusable components. The knowledge bases give the knowledge of what to reuse and the reuse techniques provide the knowledge of how to both reuse existing components and extend the library as existing components are adapted or new components are created.

The above explanation, describes the relationships within the reuse process between the four players. However, these players should not only be examined individually, as they are related, e.g., the designers (potential customers) may be adversely influenced by Not-Invented-Syndrome (competitor). To win this customer from the competitor and convert him over to reuse, training (which is a complementor) can be given to the designers about the advantages of the reuse process; for example, the designers can be educated about how to reuse the reusable components. Designers will also be better motivated if a reuse library (complementor) is well organised, and the components are easy to find and reuse, and if it is straightforward to determine which reusable components meet the requirements of a particular specification. Furthermore, management can create competition among the designers, or motivate the designers initially by rewarding their efforts, both in making use of reusable components and in making new components easier to reuse. The relationships of each actor with other actors in the value net need to be studied in detail. This information can then be used to find the points of leverage. The points of leverage may be different for different companies. The reuse value net provides all the necessary information to implement a reuse process, and hence can be used as a good analysis tool.

\section{Research methodology}

To successfully attempt reuse, an organization must systematically address a wide range of both technical and non-technical problems. There is no guaranteed recipe for successful reuse, each organization must analyse its own needs, implement reuse measurements, define the key benefits it expects, and manage risk (Frakes \& Isoda, 1994). It is however worth the efforts, as companies that make a better job of 
understanding their domains and implementing systematic reuse will gain a powerful competitive advantage. Instituting reuse may require an organization to change the ways in which it conducts its business, and such changes may bring many previously hidden managerial, cultural, social and economical issues to the surface (Davis, 1994). Without a reuse-driven software development process to guide them, system developers will not achieve many of the benefits of sharing and reuse. One of the main objectives of this research is to design an efficient reuse process. To achieve these objectives a Reuse agent; an intelligent software program (tool) has been designed.

\section{[Insert figure 5 somewhere here]}

Figure 5 shows the experimental environment. The experimental environment consists of a knowledge base, which is populated by knowledge about different scenarios in reuse implementation and solutions to overcome the difficulties that can arise during implementation. Before designing a reuse process for an organisation the Reuse Agent needs to collect information about the design and development environment that currently exists in the organisation, and identify how developers (design engineers) and management currently view and practise reuse within this environment. To collect this information the Reuse Agent uses two questionnaires, one questionnaire seeks information about management support for reuse in the organisation, and the second questionnaire seeks information about the present reuse scenario and the designer viewpoints about reuse. Each questionnaire is designed to collect information relating to the present training facilities regarding reuse and the tools to encourage or support reuse that may currently be available. The questionnaire response information from management and developers is collected in a database (labelled Response Data in figure 5) and is then fed to the Reuse Agent. The Reuse Agent then processes the information using its knowledge base and uses it to formulate a Reuse Value Net for the organisation.

The reuse value net helps to identify relationships between different reuse factors and any factors that are inhibiting the reuse implementation process. Knowledge of the interdependencies between the reuse factors, coupled with information from the knowledge base and example reuse processes help the Reuse Agent to formulate a reuse process pattern for the organisation.

The reuse value net identifies the "what", i.e. what should be done to achieve efficient reuse and the "who", i.e. the factors and actors involved in the reuse process. However, to achieve efficient reuse, the "when" and "how" of practicing reuse must also be known. In the current research, patterns have been identified as a means to answer these questions. Patterns capture knowledge that experts apply in solving recurring problems (Rising, 2002). One common definition is that a pattern is a solution to a problem in a context. Hence in the context of the current research, the expertise of an experienced designer is being reused when a pattern is applied. Two pattern approaches have been combined, i.e. process pattern and design pattern approaches. The combined use of process and design patterns in this approach to reuse is described in greater detail in (Dani \& Harding 2003). The process patterns are used to guide the designer about how the reuse process works, and a design pattern provides a scheme for refining the subsystems or components of a software system, or the relationships between them. The design pattern describes the 


\section{Revised Version \\ Page 7 of 21}

commonly recurring structure of communicating components that solve a general design problem within a particular context. The design patterns are used to store the reusable models for future reuse.

A process pattern is a collection of general techniques, actions, and/or tasks (activities) for developing reusable designs, models or software components. A process is defined as a series of actions in which one or more inputs are used to produce one or more outputs. A pattern is a general solution to a common problem or issue, one from which a specific solution may be derived. In other words, a process pattern is a pattern, which describes a proven, successful approach and/or series of actions for developing reusable components. An important feature of a process pattern is that it describes what you should do but not the exact details of how you should do it. When applied together in an organised manner, process patterns can be used to construct a software or information reuse process for a particular organization.

Figure 5 also illustrates the use of Process Patterns along with the Reuse Value Net. The Reuse Process Patterns are stored in the reuse library. The complementors are the reusable tools, which in this case are the design pattern and process pattern catalogues. These can then be invoked in order to find the relevant reusable models for the particular reuse project. The Reuse Value Net can also be used to identify the points of leverage. The use of the Reuse Value Net and process patterns to guide developers in the reuse process is explained through an example in the next section.

\section{An example to illustrate the experimental software}

Company $X$ are global manufacturers of widgets from several product families. When a new product is designed they use simulation models to design suitable manufacturing cells to produce the product, and meet their throughput, cost and delivery objectives. It is a time consuming and expensive task to build and evaluate new simulation models. They therefore wish to introduce a Reuse Project to improve their reuse of existing information and simulation models.

The Reuse Agent is used to determine appropriate activities during the Reuse Project. Questionnaires are sent to members of management and design / modelling teams, to establish whether any reuse activities currently exist in the company. The completed questionnaires are collected and the response data stored in the database. Company $\mathrm{X}$ has never formally practised reuse in the past. However, the questionnaires are designed to also identify whether individual design engineers are reusing components informally; this may be by using elements of models they have previously built, or even working informally with colleagues and sharing components.

The Reuse Agent processes the response data, and in this case, the analysis of the questionnaires identifies that

1. The designers are not currently practising reuse, they are designing systems from scratch.

2. When they work on a new project, they generally do not try to reuse code or models from previous projects.

3. Most of the designers have never tried to reuse code or models created by other designers.

4. There are no formal incentive programs or mechanisms to motivate reuse either in place or planned. 


\section{Revised Version \\ Page 8 of 21}

5. No reuse library or reuse catalogue currently exists in the organisation.

6. The only sharing across business units that currently exists is of software applications.

The Reuse Agent analyses these results and determines that the following problem areas need to be addressed initially:-

(i) The designers are using traditional design methods. (These act as an obstacle to reuse).

(ii) Even if the designers want to practice reuse there is nothing to reuse.

(iii) Training in reuse techniques should be provided.

These are highlighted in the following value net that the Reuse Agent forms for the organisation.

\section{[Insert figure 6 here]}

In the analysis for the reuse value net it was found that the design engineers in the company use traditional design methods. This is an obstacle to reuse since the engineer are likely to feel that as what they are already doing produces satisfactory results, why should they change their approach? The adoption of any new techniques or tools inevitably causes a certain amount of pain through the learning period, before benefits are really felt. Hence Company X will need to provide some motivation and incentives to promote the different ways of working required to make reuse effective. Reuse is not currently actively used in Company X. Answers from the questionnaires suggested that when individual designers begin a new simulation model, they may sometimes study previous models they have worked on for ideas. However, a major obstacle to reuse was identified as there are no easily available, convenient components that can be reused. To solve the identified problems, the Reuse Agent recommends the creation of a Reuse Library and Catalogue to store the reusable components, and the adoption of different reuse techniques to encourage the design engineers in the company to reuse these components. To support its recommendations, the Reuse Agent then consults the Reuse Process Patterns database (shown in figure 5) and suggests activities that need to be undertaken to progress the reuse project.

\section{[Insert figure 7 about here]}

The role and behaviour of the Reuse Agent in this example are summarised in figure 7. The experimental set up (from figure 5) is shown in the top left of figure 7. As explained, the Reuse Agent initially uses its knowledge to analyse the questionnaire response data and produce a Reuse Value Net. The bold dotted arrow marked "Stage 1 " in figure 7, shows the Reuse Value Net that is produced for Company $\mathrm{X}$ in this example. The elements highlighted in bold text show aspects requiring immediate attention. Typically two different types of problem may be identified through the Reuse Value Net, and these have been marked "*1" and "*2" in figure 7. Problems in the area marked "*1" are competitors, and therefore must be tackled by either decreasing their influence or by increasing the influence of reuse (to make reuse a more competitive option). 


\section{Revised Version}

Possible solutions recommended by the Reuse Agent are also shown in figure 7 to the right of the Reuse Value Net. This is indicated by the bold dotted arrow marked "Stage 2". In this example, the recommended solution to problem "* 1" is to promote reuse by providing incentives. As indicated by the arrows in the experimental set up figure, the Reuse Agent would also provide a process pattern showing steps that can be taken to achieve this. This is indicated by the bold dotted arrow marked "Stage 3". Detailed process pattern steps are not given in figure 7 for problem 1, due to space limitations. However, these steps would include, for example, activities such as setting up a bonus scheme to reward productivity increases through reuse of components and introduction of staff performance measures to assess whether reuse is being used effectively and whether staff are making it easy for others to reuse their components. The process steps suggested by the Reuse Agent are generic in form and need to be specialised by engineers within Company $X$ to suit the requirements and environment of that individual company. The Reuse Agent can guide users through the important steps of specialisation, such as the identification of suitable metrics for measurement of productivity, determination of periods of measurement, establishment of types and levels of incentives, etc. However, the actual details have to be decided by the management and users within the company, as successful applications of reuse will inevitably be different and specific to individual companies.

Problems identified in the Reuse Value net in the area marked "*2" on figure 7 relate to complementors, and typically any problems in this area indicate the absence of some key elements which are necessary to enable or facilitate reuse. They therefore must commonly be tackled by the provision of additional resources of some kind. In the example of Company $\mathrm{X}$, there are three important activities that should be undertaken:

- Building a Reuse Library.

- Retrospective creation of reusable components from existing sources and

- Ongoing creation of reusable components from current and new projects (this must continue as an ongoing activity).

In figure 7, these three solutions are shown as 2.a, 2.b and 2.c.

Once again the Reuse Agent can guide users through the activities necessary to provide solutions to these identified problems by indicating useful steps to developing these necessary resources. Again, the process pattern steps suggested by the Reuse Agent are generic, and need specialising to suit the needs of the particular company. In figure 7 , some example steps are provided for the solution $2 \mathrm{~b}$ (and these will be specialised to enable the selection of reusable components from Company X's existing simulation models and information models). These steps are comprised of different Stage and Task Process Patterns, and this is demonstrated in further detail in the Task Process Patterns and the Stage Process Patterns shown in figure 8.

\section{[Insert figure 8 about here]}

The first task shown in figure 8 is to Determine the types and sources of reusable components. This is the first step in the Selecting Reusable Components Process Pattern. If users request guidance on how to proceed with this task, the Reuse Agent can provide assistance through further process patterns. Hence the Domain Analysis Process Pattern (figure 8) would guide the user through an analysis of the domain, so that Company $\mathrm{X}$ would be encouraged to determine detailed requirements it has for 
simulation modelling, and the resources and facilities that it are needed to satisfy these requirements. Company $\mathrm{X}$ must also consider the types of simulation models that are likely to be required. This would include the key elements, resources and types of processes and structures that are used within the models and the information sources that are used to populate details of capabilities, requirements etc within the models. Having completed the domain analysis, figure 8 shows that Company $\mathrm{X}$ would then be guided to examine its existing systems, to identify which of the key elements already exist and then to look for similarities. If the same (or very similar) resource(s), processes or sub-processes commonly occur in models, these will be prime candidates for classification as "reusable components". If similar elements exist, the differences between them need to be examined to determine whether the differences are essential for the requirements of the individual cell that is being simulated, or are some of the differences purely due to individual designer preferences. Company X can be guided through these sorts of activities and decisions by the Reuse Agent, using the Creating a Reusable Component Process Pattern (as shown in figure 8).

The Reuse Agent can also guide design engineers and management through the necessary activities for achieving solutions 2.a and 2.c in a similar manner. The domain analysis carried out for solution 2.b is also an important requirement for both $2 \mathrm{a}$ and $2 \mathrm{c}$. Hence knowledge acquired during this stage will provide valuable background knowledge for the building of the Reuse Library with good catalogues and determining which elements of current projects should also be stored in the Reuse Library as reusable components. Classification and cataloguing of the reusable components in ways that make it quick and easy for design engineers to determine whether a particular component meets their requirements is an important incentive for encouraging reuse.

\section{Conclusion}

An appropriate and efficient reuse process must be designed before it can be applied to the field of manufacturing system design. Reuse often fails because it is generally approached as an independent collection of tools and techniques, and the technical and non-technical aspects are commonly examined separately. This research proposes that all the factors affecting reuse are interdependent and therefore should be studied simultaneously. By understanding the interdependencies between various factors involved in the reuse process, an efficient reuse process can be designed. The concept of a reuse value net is proposed in this paper, and this enables the roles of the various factors affecting reuse to be studied. The value net theory has been applied to the reuse process and the various factors affecting reuse are mapped to formulate a reuse value net. Further work is required in order to study the interdependencies between the various factors in detail. The authors have identified a number of case studies and thorough experimentation is underway to demonstrate and evaluate the application of the reuse value net in achieving efficient manufacturing system design.

\section{References:}

1. Ambler, S., 1998, Process Patterns: Building Large-Scale Systems Using Object Technology (Cambridge University Press). 
2. Bhatnagar, R., and Viswanathan, S., 2000, Re-engineering global supply chains: Alliances between manufacturing firms and global logistics services providers, International Journal of Physical Distribution \& Logistics Management, 30(1), 13-34.

3. Busby, J.S., 1999, The problem with design reuse: an investigation into outcomes and antecedents, Journal of Engineering Design, 10(3), 277-296.

4. Davis, T., 1994, Adopting a policy of reuse, IEEE spectrum, June-1994, 4448 .

5. Dani, S. S., and Harding, J. A., 2003, A Pattern-driven approach to Reuse in Manufacturing System Design, Working paper, Product Realisation Technologies Research Group, Wolfson School of Mechanical and Manufacturing Engineering, Loughborough University, Leicestershire. UK.

6. Fafchamps, D., 1994, Organizational factors and reuse, IEEE software, Sept.1994, 31-41.

7. Frakes, W., B. and Isoda, S., 1994, Success factors of systematic reuse, IEEE software, Sept. 1994,14-19.

8. Harding, J. A. and Popplewell, K. 1998, Simulation: An Application of Factory Design Process Methodology, Journal of Operations Research Society, 51, 440-448.

9. Harding, J. A., Yu, B., and Popplewell, K. 1999, Information modelling: an integration of views of a manufacturing enterprise, International Journal of Production Research, 37(12), 2777-2792.

10. Henry,E. and Faller,B. 1995, Large-scale industrial reuse to reduce cost and cycle time, IEEE software, Sept.1995, 47-53.

11. Lim,W.C., 1994, Effects of reuse on quality, productivity, and economics, IEEE software, Sept.1994, 23-31.

12. McClure, C., 1997, Software reuse techniques: adding reuse to the system development process (Prentice Hall).

13. Nalebuff, B.,J. and Brandenburger, A.,M., 1996, Co-opetition: 1)A revolutionary mindset that combines competition and cooperation 2) The Game Theory strategy that's changing the game of business (Haper Collins Business).

14. Rabbino, H., Applying the Principles of Co-opetition With System Dynamics Tools, SDSG, LLC (The Strategic Decision Simulation Group), http://www.sdsg.com/ 


\section{Revised Version}

Page 12 of 21

15. Rine, C. D. and Nada, N., 2000, Software Reuse Reference Model: Development and Validation, Journal of Information and Software Technology, 42, 47-65.

16. Rising Linda, 2002, Reuse at AG Communication Systems = Patterns, http://www.agcs.com/supportv2/techpapers/patterns/papers/multi.htm (first published in MultiUse Express, Vol. 4, No. 3, June 1996, p.3.)

17. Sivaloganathan, S., Shanin, T. M., 1999, Design Reuse: An Overview, Proceedings of the IMECH E Part B Journal of Engineering Manufacture, 213(7), 641-654.

18. Yu, B., Harding J.A., and Popplewell,K., 2000, A Reusable enterprise model, International Journal of Operations \& Production Management, 20(1), 50-69. 


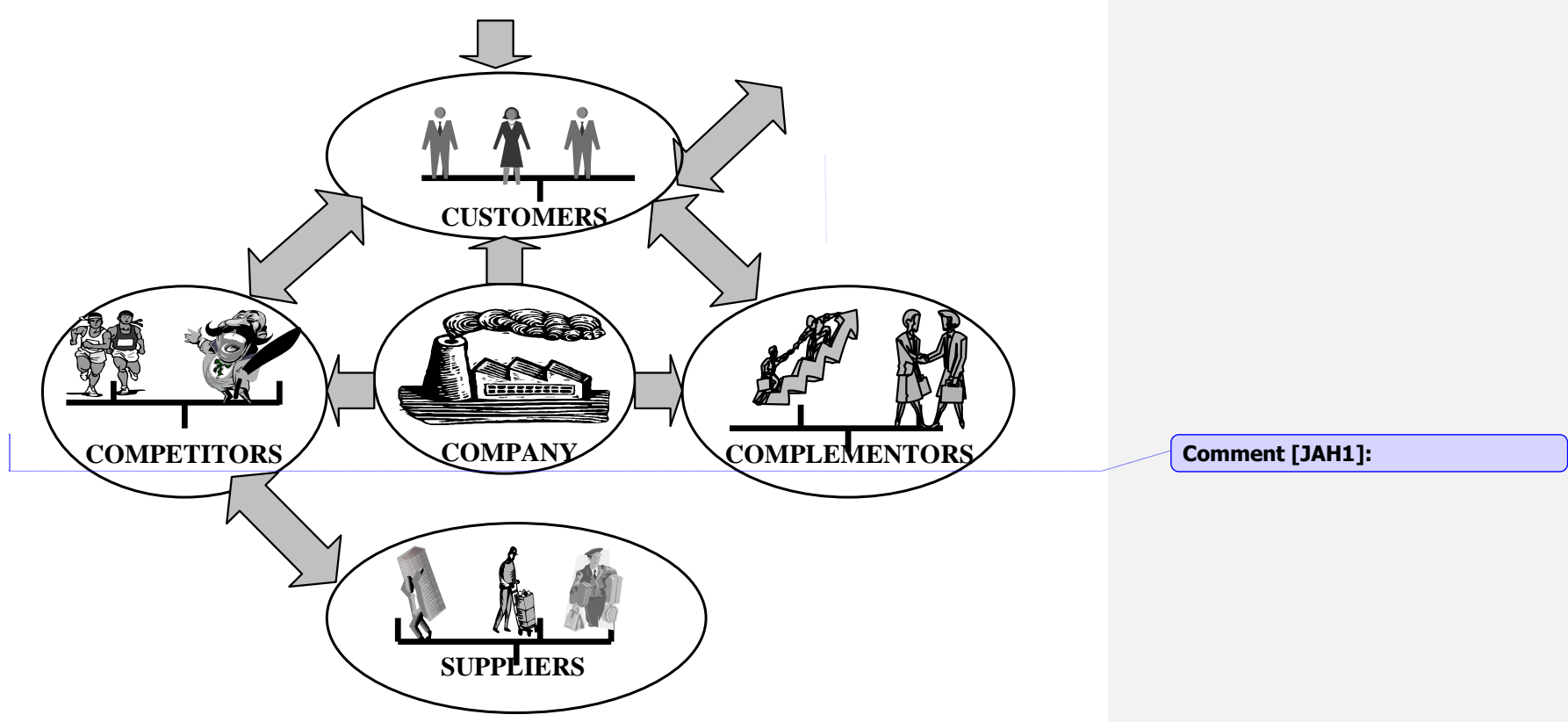

Figure 1 
Revised Version

Page 14 of 21

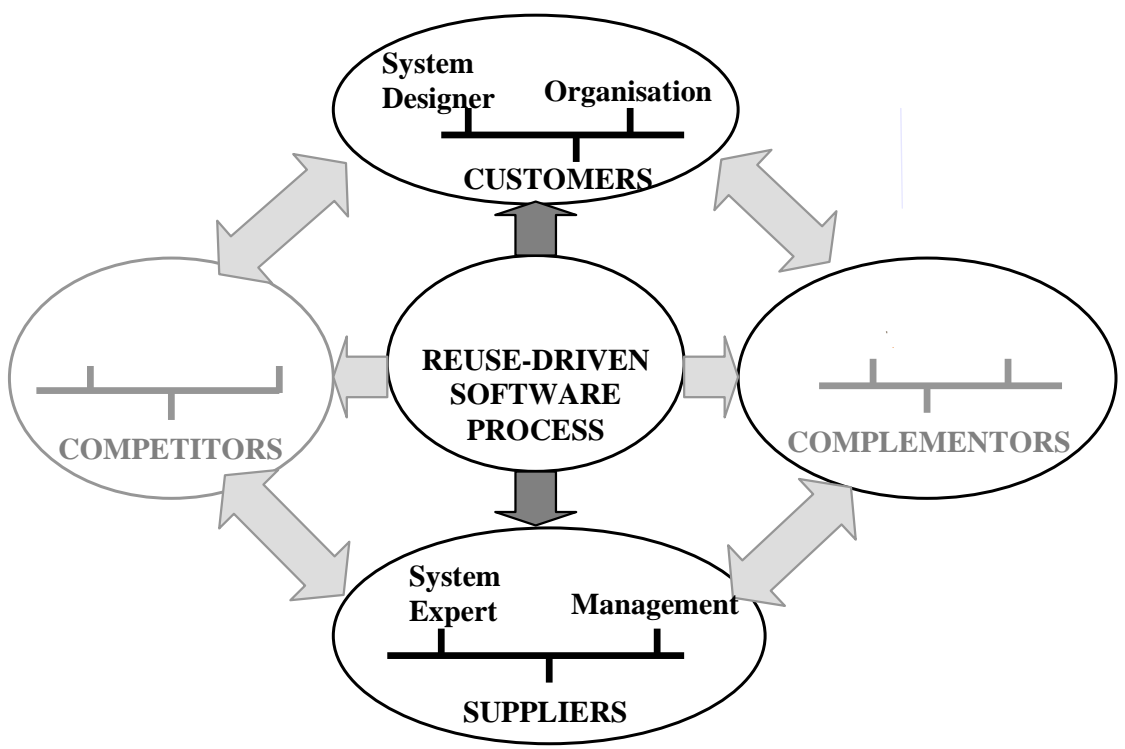

Figure 2 
Revised Version

Page 15 of 21

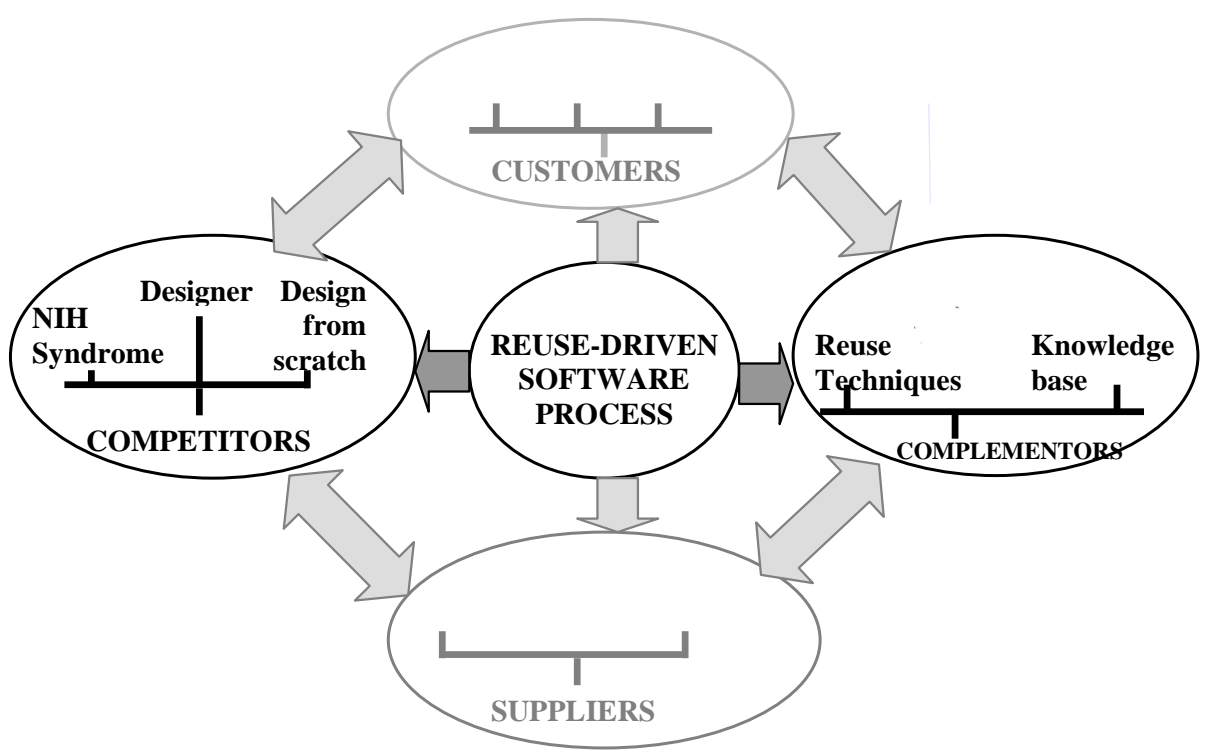

Figure 3 


\section{Revised Version}

Page 16 of 21

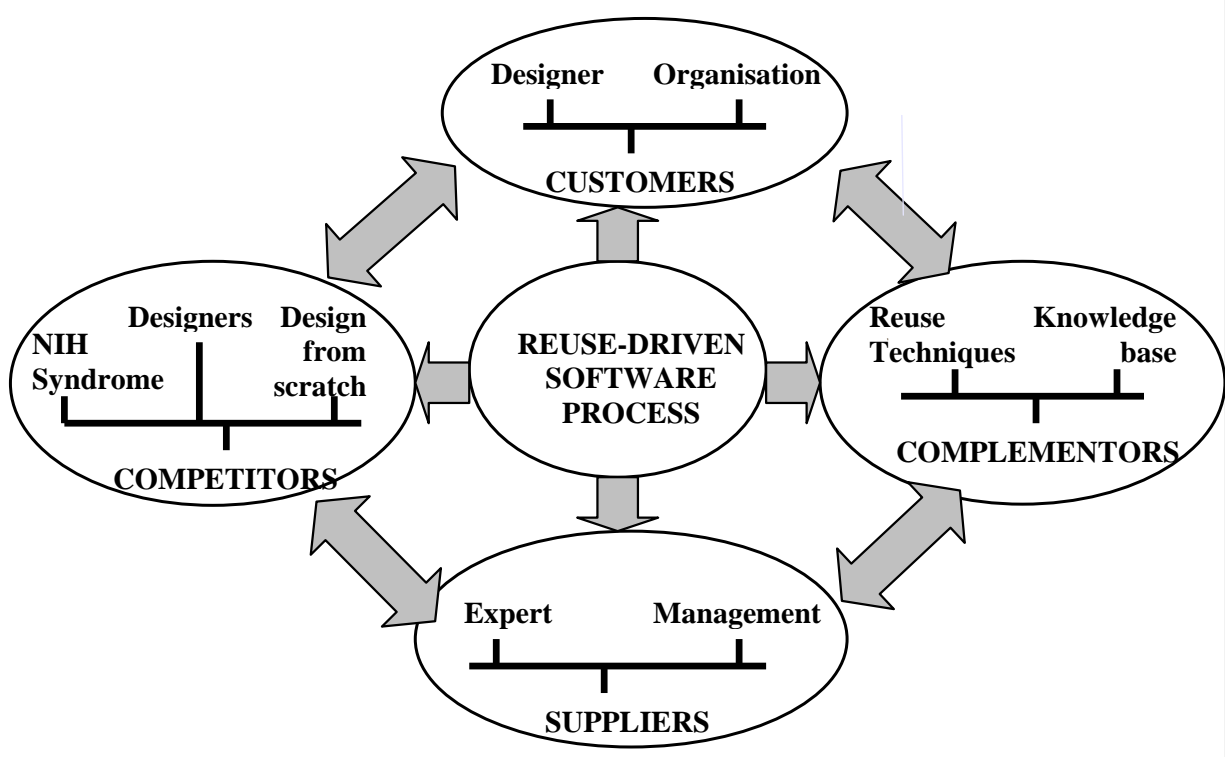

Figure 4 
Revised Version

Page 17 of 21

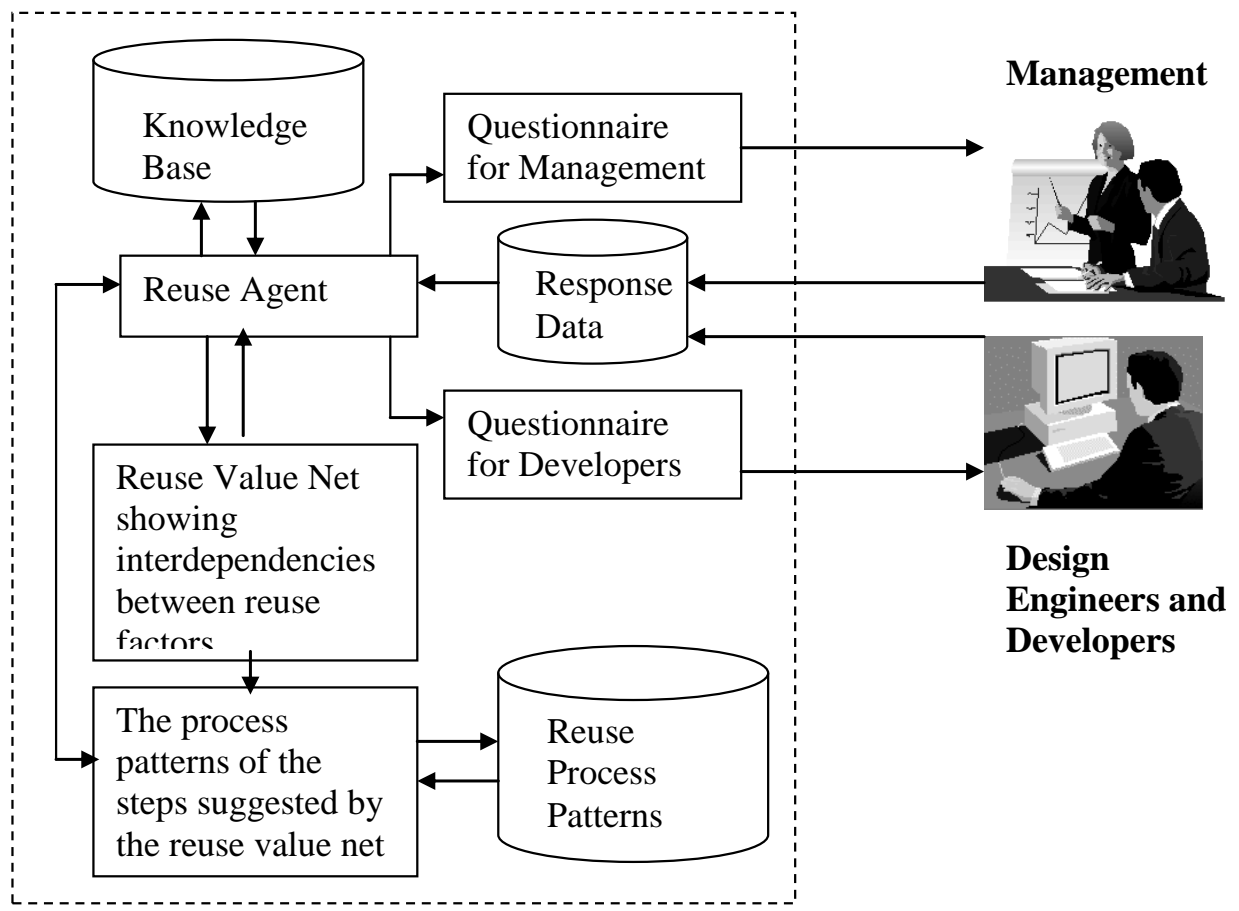

Figure 5 
Revised Version

Page 18 of 21

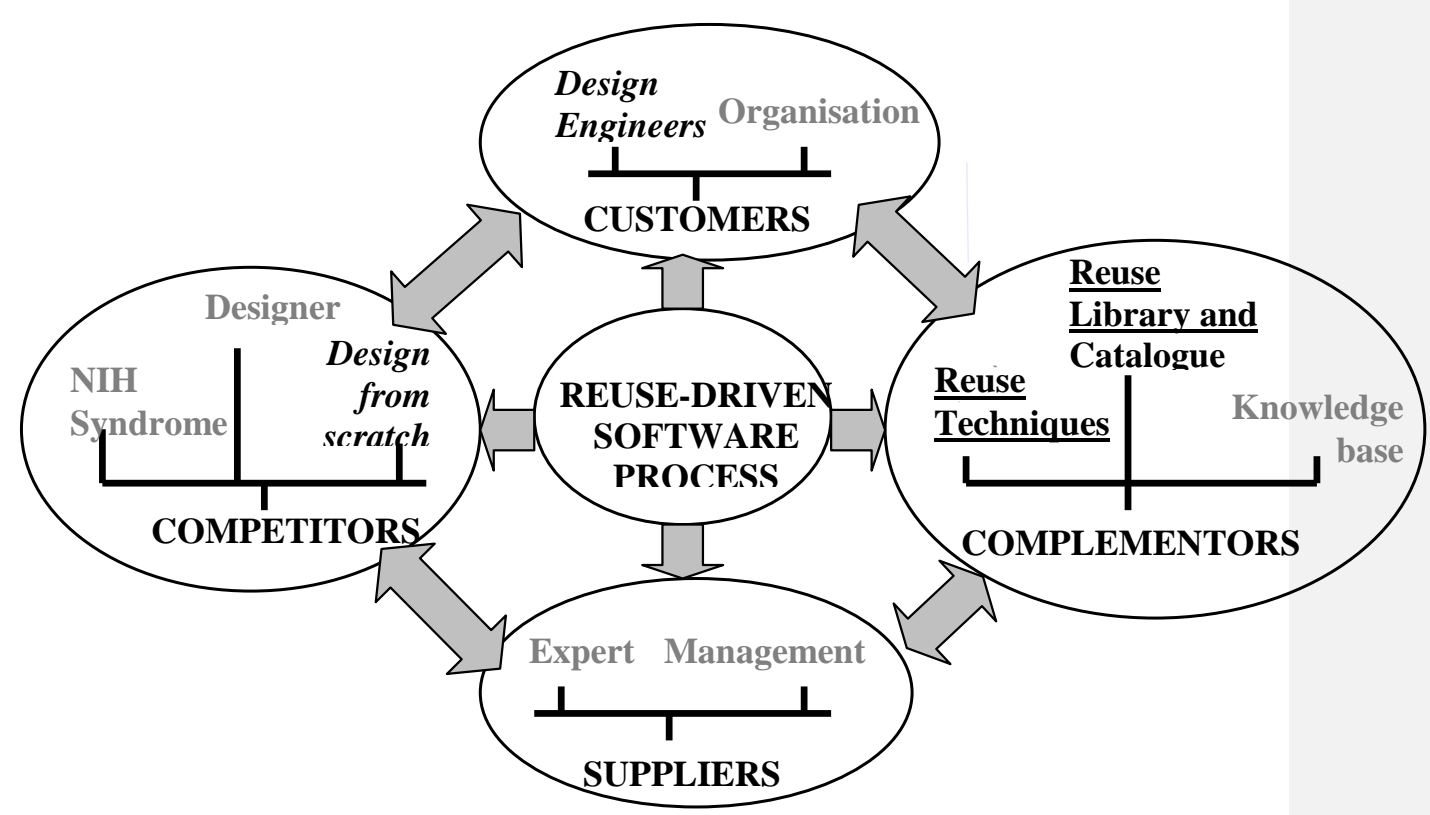

Figure 6 


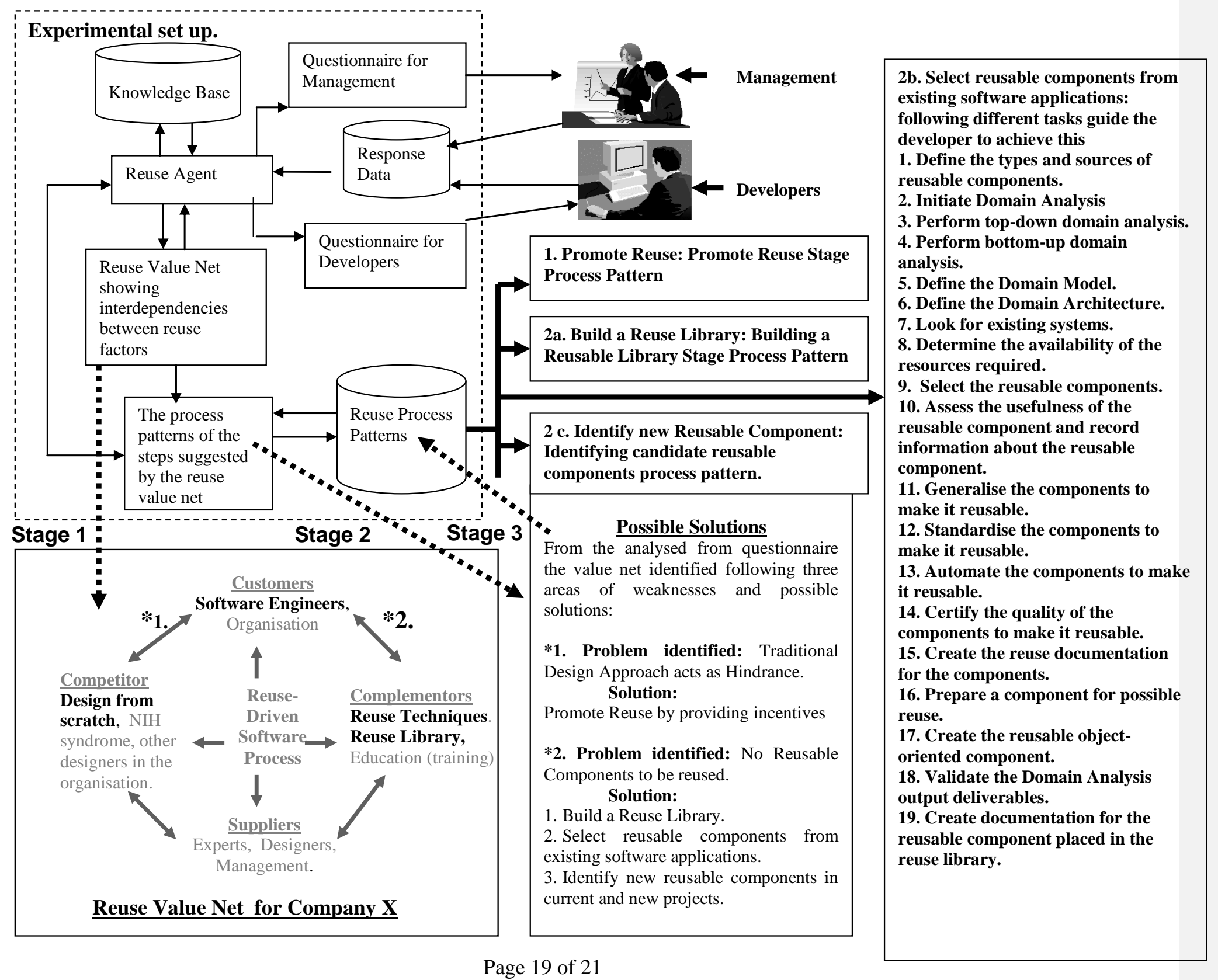

Page 19 of 21 


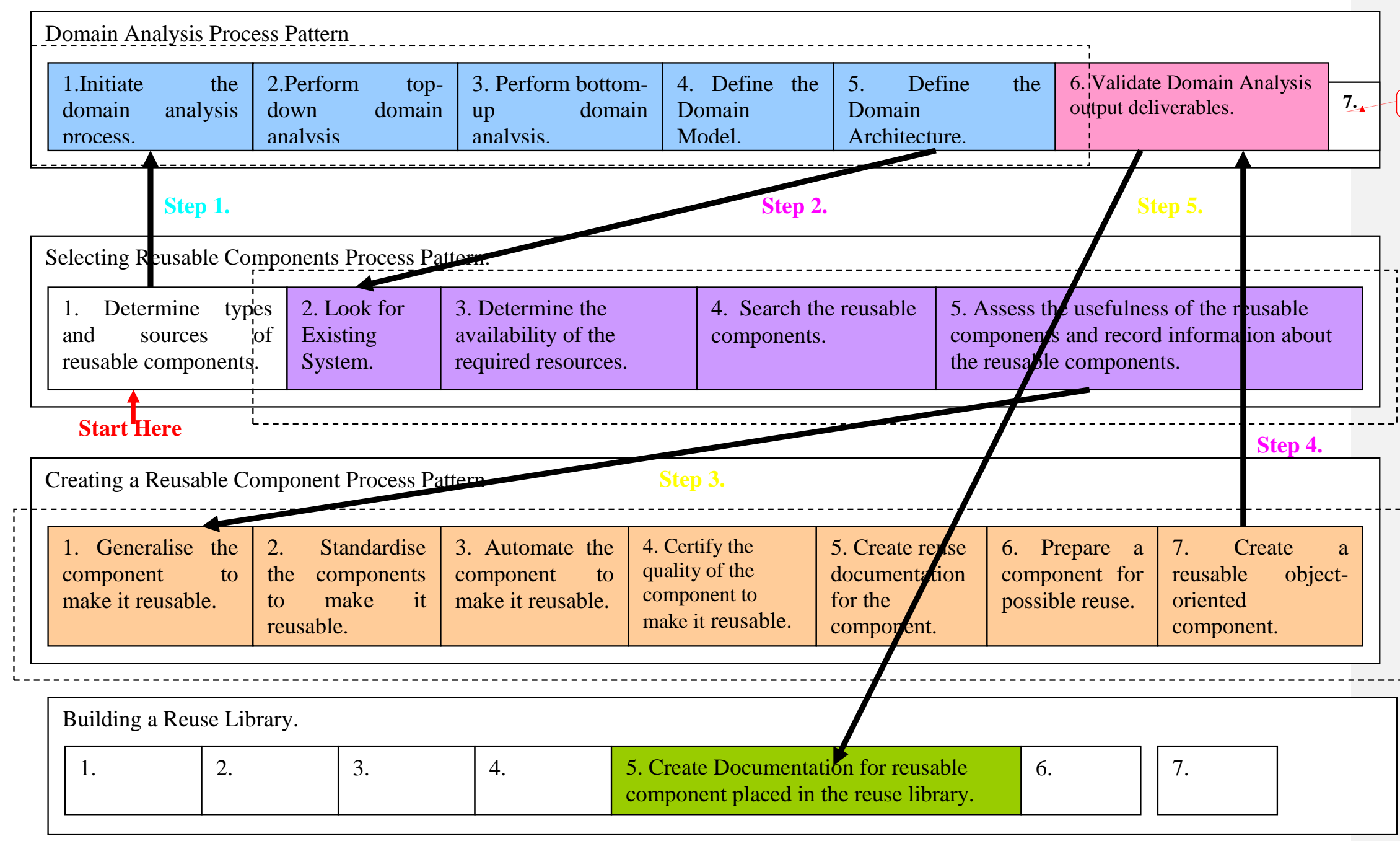




\section{List of figures}

Figure 1 The Value Net (adopted from Nalebuff, Brandenburger, 1996)

Figure 2 The suppliers and customers in the Reuse Value Net

Figure 3 The complementors and competitors in the Reuse Value Net

Figure 4 Reuse Value Net

Figure 5 Experimental set up

Figure 6 Reuse Value Net for Example

Figure 7 Example Application of Reuse Agent

Figure 8 Process Patterns approach for Reuse Value Net Solutions 